\title{
Restorative Effects of Platelet Derived Growth Factor-BB in Rodent Models of Parkinson's Disease
}

\author{
Olof Zachrisson ${ }^{\mathrm{a}}$, Ming Zhao ${ }^{\mathrm{b}}$, Annica Andersson ${ }^{\mathrm{a}}$, Karin Dannaeus ${ }^{\mathrm{a}}$, Johan Häggblad ${ }^{\mathrm{a}}$, \\ Ruben Isacson ${ }^{\mathrm{a}}$, Elisabet Nielsen ${ }^{\mathrm{a}}$, Cesare Patrone ${ }^{\mathrm{a}, \#}$, Harriet Rönnholm $^{\mathrm{a}}$, Lilian Wikstrom ${ }^{\mathrm{a}}$, \\ Kristofer Delfani ${ }^{\mathrm{b}}$, Alison L. McCormack ${ }^{\mathrm{c}}$, Theo Palmer ${ }^{\mathrm{c}}$, Donato A. Di Monte ${ }^{\mathrm{c}}$, Michael P. Hill ${ }^{\mathrm{d}}$, \\ Ann Marie Janson Lang ${ }^{\mathrm{b}, *}$ and Anders Haegerstrand ${ }^{\mathrm{a}, *}$ \\ ${ }^{\mathrm{a}}$ NeuroNova AB, Fiskartorpsvägen 15, Stockholm, Sweden \\ ${ }^{\mathrm{b}}$ Department of Neuroscience, Karolinska Institutet, Stockholm, Sweden \\ ${ }^{\mathrm{c}}$ The Parkinson's Institute, Sunnyvale, CA, USA \\ ${ }^{\mathrm{d}}$ Motac Neuroscience Ltd, Manchester Science Park, Manchester, UK
}

\begin{abstract}
Parkinson's disease is characterized by motor deficits caused by loss of midbrain dopaminergic neurons. Neurotrophic factors and cell transplantation have partially restored function in models of Parkinson's disease, but have had limited effects in humans. Here we show that intracerebroventricular administration of platelet-derived growth factor-BB can offer an alternative strategy to restore function in Parkinson's disease; In animal models of nigrostriatal injury, a two weeks treatment with plateletderived growth factor-BB resulted in long-lasting restoration of striatal dopamine transporter binding sites and expression of nigral tyrosine hydroxylase. It also normalized amphetamine-induced rotational behavior in 6-hydroxydopamine lesioned rats. Platelet-derived growth factor-BB promoted proliferation of neural progenitor cells in the subventricular zone. The effects on dopaminergic neurons and functional recovery could be blocked by co-infusion with a proliferation inhibitor, indicating a link between the proliferative and anti-parkinsonian effects. Based on the current data, we consider platelet-derived growth factor-BB a clinical candidate drug for treatment of Parkinson's disease.
\end{abstract}

Keywords: Platelet derived growth factor, Parkinson's disease, subventricular zone, progenitor cell, 6-hydroxydopamine, MPTP

\section{INTRODUCTION}

Parkinson's disease (PD) is a common neurodegenerative disease with the cardinal signs of resting tremor, slowness of movement (bradykinesia) and

\footnotetext{
*Correspondence to: Anders Haegerstrand, NeuroNova AB, Fiskartorpsvägen 15, SE-11433 Stockholm, Sweden. E-mail: anders. haegerstrand@neuronova.com; Ann Marie Janson Lang, Department of Neuroscience, Karolinska Institutet, SE-17177, Stockholm, Sweden. E-mail: am.janson-lang@ki.se.

\# Present address: Karolinska Institute, Department of Clin Sci and Edu., Unit for Diabetes Research, Södersjukhuset, SE-11833 Stockholm, Sweden
}

rigidity. Symptoms are largely attributable to a progressive loss of dopaminergic (DA)-ergic neurons in the substantia nigra pars compacta $(\mathrm{SNpc})$ and as a consequence, an impaired DAergic input to the striatum and other brain regions. There is a significant medical need for treatment strategies that could modify the disease and restore some of the functionality of the degenerating nigrostriatal neuronal pathways. Two restorative approaches, supplying protein factors that can rescue dying DAergic neurons or transplanting DA-producing cells, have been explored for more than two decades, both preclinically and clinically. The most extensively investigated strategies are intracerebroventricular (i.c.v.) or intraparenchymal delivery of 
glial cell line-derived growth factor (GDNF) or embryonic cell/tissue grafting into striatal regions. While these approaches have been effective in various animal models, the results of clinical placebo-controlled trials have been so far disappointing [15, 25, 33]. Most recently, moderately positive clinical results have been reported using the GDNF-like protein neurturin delivered via an adeno-associated viral vector [28]. Overall however, it remains important to identify other mechanisms relevant to restoration of DA-functionality.

The platelet-derived growth factor (PDGF) family comprises growth factors that act via tyrosine kinase receptors. The PDGFs stimulate various cellular functions such as proliferation, growth and differentiation. The PDGF-BB isoform, but not -AA, has been shown to increase survival of DAergic cells in vitro, suggesting that it's in vivo administration could be beneficial in PD [34, 38]. PDGFs promote the proliferation of glial precursor cells and are possibly important to maintain a pool of neural and glial precursor cells in the brain $[12,13,22]$. In line with this, PDGFs potentiate proliferation, migration and neuronal differentiation in vivo in the subventricular zone (SVZ) and striatum [21,30]. The SVZ is located in the walls of the lateral brain ventricles and known to harbor neural stem and progenitor cells. Interestingly, DAergic fibers originating in the SNpc innervate the SVZ of mice [2] and nonhuman primates [16]. The SVZ in PD patients display cellular losses, in particular cells which have a regenerative capacity [20]. It has been suggested that the stem/progenitor cell niche in the SVZ is dependent on DAergic input to maintain a normal cellular turnover. The possibility that an increased cell proliferation in e.g. the SVZ could influence the DAergic system has been suggested, but not addressed in any greater detail $[4,9,12,14]$. To elucidate a potential effect of PDGF on the nigrostriatal DAergic system we investigated the effects of 14 days of i.c.v. infusion of PDGF-BB in models of PD in mice and rats. To partially address the mechanism by which an effect is mediated, we inhibited the proliferative response elicited by PDGF-BB, by co-administering a mitosis-blocker in a rat model of PD.

\section{MATERIALS AND METHODS}

\section{PDGF-BB in MPTP lesioned mice and subsequent analyses}

Two different experimental designs were used to study the effect of PDGF-BB (Sigma) in mice (C57
$\mathrm{Bl} / 6,10$ weeks old) after a lesion induced by l-methyl4-phenyl-1,2,3,6-tetrahydropyridine (MPTP; Fig. 1a, b): A, to assess the effects on cell proliferation in the forebrain, mice were given four doses of MPTP intraperitoneally (i.p.; $15 \mathrm{mg} / \mathrm{kg} \times 4,2 \mathrm{~h}$ apart). One week post-lesion, osmotic pumps linked with brain infusion kits delivered PDGF-BB at $36 \mathrm{ng} /$ day into the right lateral ventricle. The pumps also contained the proliferative marker 5-bromo- $2^{\prime}$-deoxyuridine (BrdU, $1 \mathrm{mg} / \mathrm{ml}$ ) and co-delivered the two compounds for two weeks. Mice were sacrificed two days after the end of treatment, half of the forebrain was taken for immunohistochemical evaluation and the other half for DA transporter (DAT) autoradiography. Antibodies against the following proteins were used in these mouse MPTP experiments: Doublecortin (Dcx) to identify immature neuroblasts, neuronal nuclei (NeuN) to identify mature neurons, glial fibrillary acidic protein (GFAP) to identify astrocytes, chondroitin sulphate proteoglycan 4 (NG2) to identify immature oligodendrocytes, Iba-1 to identify monocyte lineage cells (such as microglia and macrophages) as well as a vascular stain (tomato lectin) to identify endothelium and pericytes. B, to assess PDGF-BB-induced neurorestorative effects on the MPTP-lesioned midbrain, a single dose of MPTP $(40 \mathrm{mg} / \mathrm{kg}$, s.c.; [8]) was given $3 \mathrm{~h}$ before i.c.v. administration of PDGF-BB (36-60 ng/day) via osmotic pumps. Drug delivery for the highest dose was $0.1 \mu \mathrm{g} / \mathrm{h} / \mathrm{kg}$ body weight. The treatment lasted for 7 days. One week or eight weeks later, animals were anesthetized with chloral hydrate $(60 \mathrm{mg} / \mathrm{kg}$ i.p. $)$ and sacrificed by intracardial infusion of fixative (4\% paraformaldehyde in PBS). After dissection of the midbrain, it was divided along the ventro-dorsal midline and postfixed and cryoprotected in sucrose. Cryostat sections were prepared as follows: one hemisphere was sectioned into $40 \mu \mathrm{m}$ sections throughout the midbrain, which contains SNpc. A randomly chosen series of every 6th section was used for free-floating immunohistochemistry using a polyclonal anti-TH antibody (Pel-Freeze, diluted 1:400) to identify DA neurons in the tissue. To visualize the antibody, the avidinbiotin peroxidase kit (Vector), with $0.03 \% \mathrm{DAB}$ as chromagen, was used adding $0.01 \% \mathrm{H}_{2} \mathrm{O}_{2}$. Cresyl violet was employed to visualize the nucleolus in neuronal nuclei, Nissl substance in neurons and the nucleus in glia cells [23]. The total number of TH-positive/cresyl violet positive neurons in $\mathrm{SNpc}$ was estimated with the optical fractionator as published earlier $[8,23$, 43]. Briefly, the slides were viewed using $100 \times$ oilimmersion objectives with a numerical aperture of 1.4. With a random start outside $\mathrm{SNpc}$, counting frames 


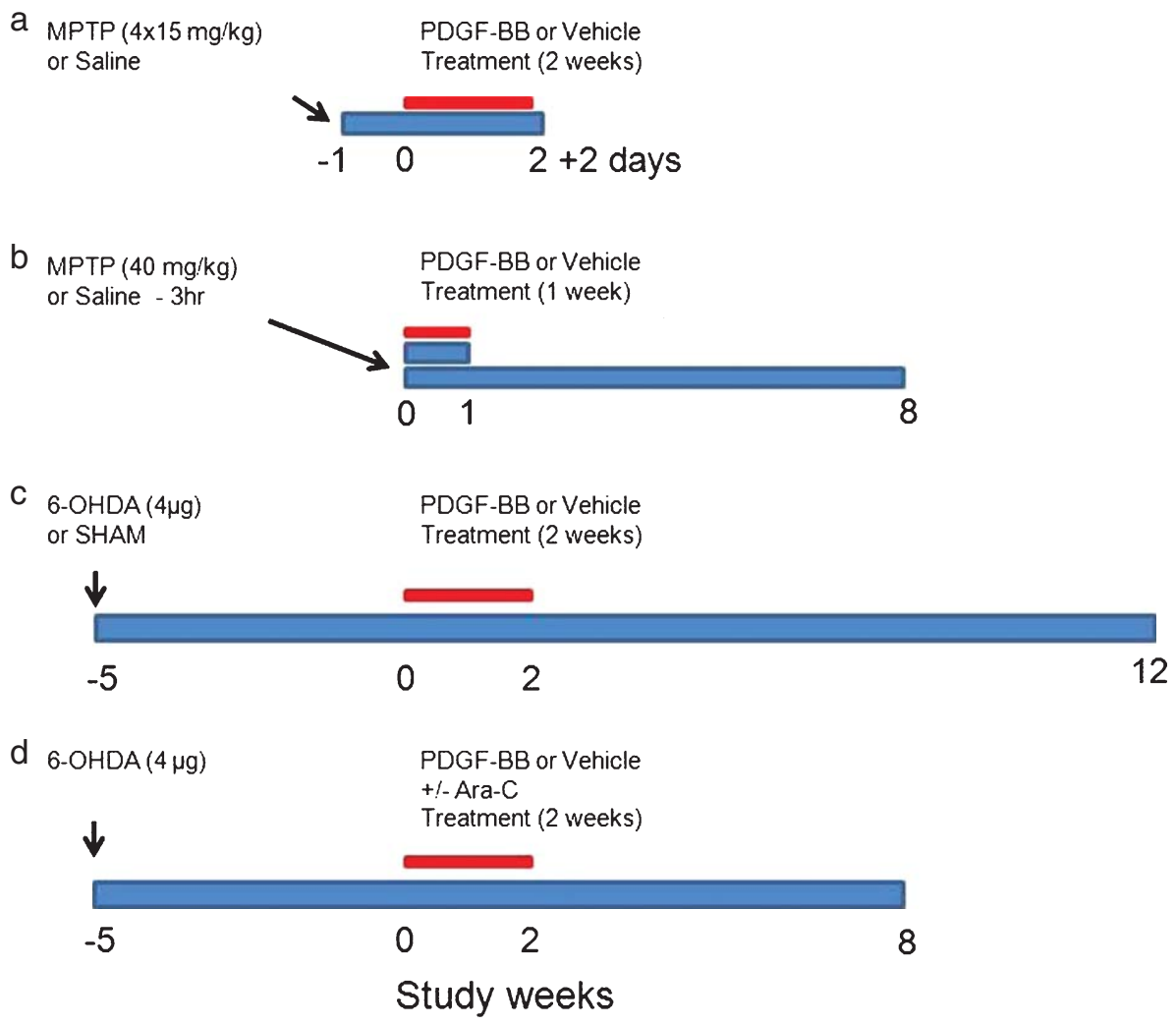

Fig. 1. Timelines illustrating the various experimental designs, a, mouse proliferation and cell fate experiments. MPTP or saline were given 1 week prior to a 2 weeks treatment with vehicle or PDGF-BB. Animals were sacrificed 2 days after end of treatment, $b$, mouse restorative experiment. MPTP or saline were given 3 hours prior to a 1 week treatment with vehicle or PDGF-BB. Animals were sacrificed either at end of treatment or 7 weeks after end of treatment. c, rat rotational experiment. 6-OHDA or sham lesions were made 5 weeks prior to a 2 weeks treatment with vehicle or PDGF-BB. Animals were sacrificed 10 weeks after end of treatment (rotational assessment was carried out before treatment and weekly throughout the remainder of the experiment), d, rat Ara-C experiment. 6-OHDA lesions were made 5 weeks prior to a 2 weeks treatment with either vehicle, PDGF-BB, vehicle+Ara-C or PDGF-BB+Ara-C. Animals were sacrificed 6 weeks after end of treatment, (rotational assessment was carried out before treatment and weekly throughout the remainder of the experiment).

were systematically sampled within the $\mathrm{SNpc}$ area using an X-Y microscope stage step motor linked to a computer assisted stereology toolbox (CAST 2.0, Visiopharm, Hoersholm, Denmark). Evaluating both the total thickness of the sections and the entire SNpc area, the morphological measurements were carried out in a three-dimensional fraction of the entire SNpc volume, i.e. by means of the optical fractionator. The sampling volume in the $z$-axis extended from $4 \mu \mathrm{m}$ from the top of the section $8 \mu \mathrm{m}$ deep, thus excluding the parts of the section close to the slide or coverslip [43]. In the X-Y plane the sampling volume was determined by the counting frame. The population of nigral neurons displaying both Nissl substance (cresyl violet stain) and expressing TH immunoreactivity in the cell body/neuropil were analyzed. Only neurons with their nucleolus inside the sampling volume were counted.
The rotator was used for the cell volume estimates. Coefficient of error for each estimate was $<0.09$.

\section{6-OHDA lesioned rats}

Male Sprague-Dawley rats weighing 280-350g were housed in a temperature-controlled room under a $12 \mathrm{~h}$ light/dark cycle with free access to food and water. Thirty minutes prior to surgery, animals were injected i.p. with pargyline $(5 \mathrm{mg} / \mathrm{kg}$; monoamine oxidase inhibitor) and desipramine $(25 \mathrm{mg} / \mathrm{kg}$; noradrenaline uptake inhibitor). Rats were then placed in a stereotactic frame under general anaesthesia (Halothane). A small burr hole was made in the right side of the skull. Animals received a unilateral injection of $4 \mu \mathrm{g}$ 6-hydroxydopamine (6-OHDA; in $2 \mu \mathrm{l}$ sterile water with $0.1 \%$ ascorbic acid) or vehicle into the right 
medial forebrain bundle at co-ordinates $-2.8 \mathrm{~mm}$ from bregma, $2 \mathrm{~mm}$ lateral to the midline, and $8.6 \mathrm{~mm}$ below the skull according to Paxinos and Watson [36]. The 6-OHDA injection was made over a 5 min period using a $5 \mu \mathrm{l}$ Hamilton syringe and the dose was chosen as an optimal dose giving a partial unilateral decrease of DAT as analyzed by autoradiography; $4 \mu \mathrm{g}$ 6-OHDA elicited a $51 \pm 11 \%$ reduction in DAT binding compared to unlesioned side $(p<0.01$ paired $t$-test). $6 \mu \mathrm{g}$ 6 -OHDA elicited a $99 \pm 0.6 \%$ reduction in DAT binding compared to the unlesioned side $(p<0.001$ paired $t$-test; data not shown). This degree of lesioning is in line with data published by Barnèoud and colleagues [3] who showed that, following 6ug 6-OHDA injected into the medial forebrain bundle of 29 rats, only 13 rotated when challenged with apomorphine and were thus fully lesioned with $99.8 \%$ loss of dopamine. Of the remaining 16 rats, 11 were partially lesioned rats and rotated to amphetamine but not apomorphine and were reported to have a $72 \%$ lesion when analyzed post mortem. The rats were allowed to recover for 5 weeks following the lesion. The animals were then implanted with an Alzet minipump attached to a cannula to allow infusion of PDGF-BB ( $36 \mathrm{ng} /$ day) or vehicle into the right lateral ventricle over a period of 2 weeks (Fig. lc). The Alzet minipump was removed 1 week later. Some animals received mitotic blocker Ara-C $10 \mathrm{mg} / \mathrm{ml}$ in the minipump (Fig. 1d). Alzet osmotic mini-pump model 2002 was used for the rats with a volume of $200 \mu \mathrm{l}$, pumping rate $12 \mu \mathrm{l} / \mathrm{d}$ for 14 days.

\section{Study design rotational study}

There were 4 groups of rats, individual rats being randomly assigned to a treatment group. Initially there were 23 rats in the lesion + vehicle group, 29 rats in the lesion + PDGF-BB group and 8 rats in each sham group, treated with vehicle and PDGF-BB, respectively. In the lesion + vehicle group, 13 rats were partially lesioned and 6 were fully lesioned. One died and 3 did not display any rotation to amphetamine; in the lesion+PDGF-BB group, 17 were partially lesioned and 7 were fully lesioned. One died and 4 did not display any rotation to amphetamine. The rats were left for 10 weeks after end of treatment and sacrificed for post mortem studies. In addition, there were 2 groups of partially lesioned rats (3 rats in each) that received BrdU (+PDGF-BB or vehicle) and were killed after the 2 week infusion period. During the study the animals received $0.05 \mathrm{mg} / \mathrm{kg}$ s.c. apomorphine and $5 \mathrm{mg} / \mathrm{kg}$ i.p. amphetamine once a week to measure rota- tional response (Fig. lc). Spontaneous locomotion was assessed in an open field test using an automated activity monitoring system (AM1053, Linton Instruments, UK). The AM1053 uses an array of 48 infrared beams, 24 on each of 2 levels measuring horizontal activity and rearing movement, respectively. The activity detector operates by counting the number of times the beams change from unbroken to broken and incrementing the relevant counters.

\section{Study design Ara-C study}

The Ara-C dose was titrated by administering four randomly assigned groups of rats either vehicle alone (comprising of BrdU $1 \mathrm{mg} / \mathrm{ml}$ and $0.1 \%$ RSA in PBS), or vehicle plus $0.55 \mathrm{mg} / \mathrm{ml}, 3.3 \mathrm{mg} / \mathrm{ml}$ or $20 \mathrm{mg} / \mathrm{ml}$ Ara- $\mathrm{C}$ in the pumps. The pumps delivered the respective solution for 2 weeks. Then, the mice were sacrificed and the BrdU labeled cells were quantified in the SVZ and striatum. There was a clear dose response in the number of cells stained positive for BrdU. Although the number of BrdU cells were greatly diminished following 3.3 and $20 \mathrm{mg} / \mathrm{ml}$ Ara-C in both striatum (56\% and $74 \%$ reduction, respectively) and SVZ (53\% and $87 \%$ reduction, respectively, all values $p<0.01$, Oneway ANOVA with Dunnett's Post-hoc Test), small cells appeared around the third ventricle in the highest dose group which were not present in any other group. The morphology of the cells was affected as well and for this reason, the $20 \mathrm{mg} / \mathrm{ml}$ dose was considered too high. The final dose was set at $10 \mathrm{mg} / \mathrm{ml} \mathrm{Ara-C}$, which was aimed by extrapolation to give an approximate $68 \%$ reduction of the number of BrdU positive cells in striatum and $75 \%$ reduction in the SVZ. In the following experiment, there were four 6-OHDA lesioned groups of rats, individual rats being randomly assigned to a treatment group. One group received vehicle one group PDGF-BB (36 ng/day), one group Ara-C (10 mg/ml), and the fourth group was given both Ara-C and PDGFBB. During the study animals received $0.05 \mathrm{mg} / \mathrm{kg}$ s.c. apomorphine and $5 \mathrm{mg} / \mathrm{kg}$ i.p. amphetamine once a week to measure rotational response. The inclusion criterion was 75 rotations over one hour. Prior to pump implantation, amphetamine induced $528 \pm 174$, $475 \pm 127,430 \pm 141$ and $561 \pm 90$ net ipsiversive rotations in the vehicle $(N=7)$, PDGF-BB $(N=10)$, Ara-C $(N=7)$ and Ara-C + PDGF-BB $(N=7)$ groups, respectively. There was no difference in amphetamine induced rotations between any of the groups compared to the vehicle-treated ( $p>0.05$; Student's $t$-test). No animals rotated in response to apomorphine, i.e. only partially lesioned animals were included. The rats were 
analyzed for a further 6 weeks after the end of treatment and before being sacrificed for post mortem studies (Fig. 1d).

\section{DAT binding}

Levels were determined by receptor-radioligand binding autoradiography using the high affinity DAT compound N-(3-iodoprop-2 E-enyl)-2beta-carbomethoxy-3beta-(4-methylphenyl) nortropane (PE2I) in the striatum. The value of this measure lies in determining whether sprouting of DAergic neurons has occurred. The radiolabeling of PE2I was performed from the stannyl precursor in order to identify the DAergic nerve endings [18]. After purification, PE2I was obtained in a no-carrier-added form with a specific activity of $2000 \mathrm{Ci} / \mathrm{mmol}$ [10]. PE2I was kept in ethanol at $-20^{\circ} \mathrm{C}$ and is stable for 1 month under these storage conditions. Sections were incubated for 90 min at $25^{\circ} \mathrm{C}$ with $50 \mathrm{pM}$ PE2I in $\mathrm{pH} 7.4$ phosphate buffer $\left(\mathrm{NaH}_{2} \mathrm{PO}_{4} 10.14 \mathrm{mM}, \mathrm{NaCl} 137 \mathrm{mM}, \mathrm{KC} 1\right.$ $2.7 \mathrm{mM}, \mathrm{KH}_{2} \mathrm{PO}_{4} 1.76 \mathrm{mM}$ ) as previously described $[5,6,17]$. Following incubation, sections were washed twice for $20 \mathrm{~min}$ in phosphate buffer at $4^{\circ} \mathrm{C}$ and then dipped in distilled water at $4^{\circ} \mathrm{C}$. After drying at room temperature, sections were exposed to $\beta$-radiation sensitive film (Hyperfilm $\beta$-max, Amersham, UK) in $\mathrm{X}$-ray cassettes, for 2 days. Densitometric analysis of autoradiographs was performed using an image analysis system (Image ProPlus). The optical density was assessed in both the rostral and caudal part of the caudate-putamen defined according to a rat brain atlas. Three sections per animal were analyzed by an examiner blinded to the experimental conditions. Optical densities were averaged in each animal and converted to amount of radioactivity bound by comparison to the previously measured sections from control animals. Mean radioactivity bound and SEM was calculated for each group. Data was expressed in $\mathrm{fmol} / \mathrm{mg}$ of tissue equivalent.

\section{Immunohistochemistry of cellular markers}

Brains were cut into $14 \mu \mathrm{m}$ coronal sections using a cryostat microtome. The sections were thawed onto pretreated slides and fixed in $4 \%$ (wt/vol) paraformaldehyde/PBS for $10 \mathrm{~min}$. For tissue to be stained for BrdU, the sections were treated with $2 \mathrm{M}$ $\mathrm{HC} 1$ at $37^{\circ} \mathrm{C}$ for $30 \mathrm{~min}$ to increase accessibility of the anti-BrdU antibody to the cell nuclei. The sections were rinsed in PBS and transferred to blocking solution (PBS; $0.1 \%$ Tween; 10\% donkey/goat serum) overnight at $4{ }^{\circ} \mathrm{C}$. The following primary antibodies were used for: TH (AB152, Chemicon; 1:800), Ki67 (mouse IgG, NCL-Ki67-MM1; Immunkemi, $1: 100$ ), Sox 2 (goat IgG sc-17320; SantaCruz, $1:$ 100), PDGFRalpha (Rabbit IgG SantaCruz; $1: 100$ ), PDGFR-beta (Rabbit IgG SantaCruz; $1: 100$ ), RECA (mouse IgG Serotec; $1: 1000$ ) and BrdU (rat antiBrdU, Harlan Sera Labs; $1: 100)$. For diaminobenzidine staining, primary antibodies were applied in blocking solution for 60-90 $\mathrm{min}$ at room temperature or over night at $4{ }^{\circ} \mathrm{C}$. After washing in PBS/0.1\% Tween for $3 \times 30 \mathrm{~min}$, secondary biotinylated antibodies (goat anti-rabbit and goat anti-rat, VectorLabs) were added at a 1:200 dilution in blocking solution for $60 \mathrm{~min}$ at room temperature. The sections were washed for $2 \mathrm{~h}$ prior to treatment with Vectastain Kit (VectorLabs) according to the manufacturer's protocol. After 1 hour of washing, the BrdU-antibody complex was detected using $0.05 \%$ diaminobenzidine with $0.01 \% \mathrm{H}_{2} \mathrm{O}_{2}$, and counterstained with Hematoxylin. The sections were dehydrated in a graded series of ethanol concentrations, followed by xylene and $99 \%$ ethanol, and mounted in Pertex. For fluorescent staining, goat-anti-mouse Alexa 555, donkey-anti-rabbit Alexa 488, and donkey-anti-goat Alexa 555 were used as secondary antibodies. DAPI was used as nuclear stain. The fluoresent sections were mounted in ProlongGold anti fade mounting media (Invitrogen). Sections were visualized using a Nikon Eclipse E600 microscope and pictures taken with a Spot Insight CCD camera.

\section{RESULTS}

\section{Histological analysis of cells in MPTP-lesioned} mice

PDGF-BB was administered together BrdU for 14 days, starting one week after lesioning with MPTP $(4 \times 15 \mathrm{mg} / \mathrm{kg}$, i.p.; Fig. la). As a sign of pre-synaptic DA-system improvements, DAT was up-regulated on the side ipsilateral to the PDGF-BB treatment (Fig. 2a) when analyzed at two days post treatment $(p=0.0204$, Kruskal-Wallis ANOVA, $p=0.029$, Mann Whitney U-test, MPTP/vehicle versus MPTP/PDGF-BB). A significant increase in cell proliferation was seen in the ventricular wall and striatum (Fig. 2b, c) and BrdU positive cells were typically co-labeled with NG2, Dcx and tomatolectin, indicating proliferation of oligodendrocytic and neuronal precursor cells, as well as vascular cells, respectively (Fig. 3a-d). 
a

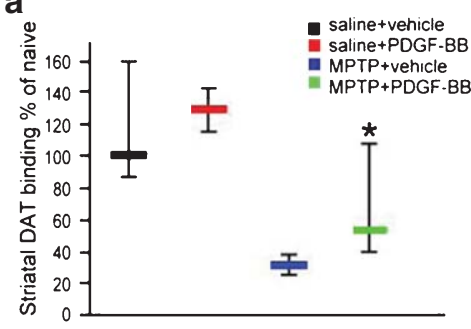

b

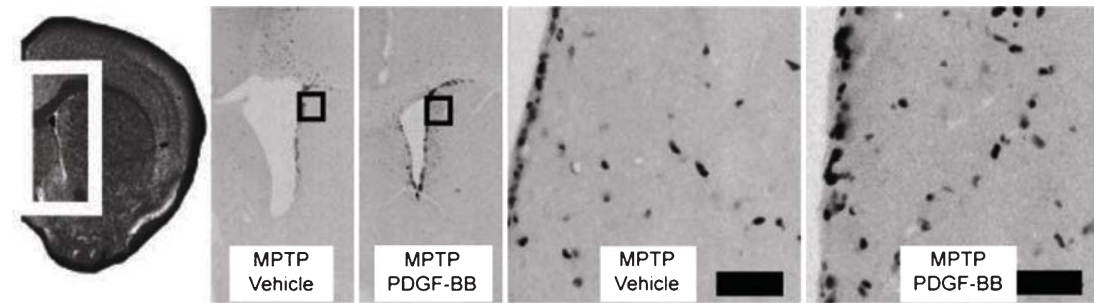

C

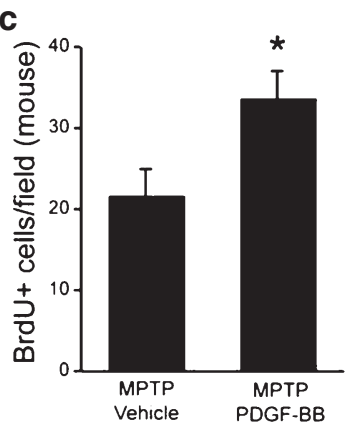

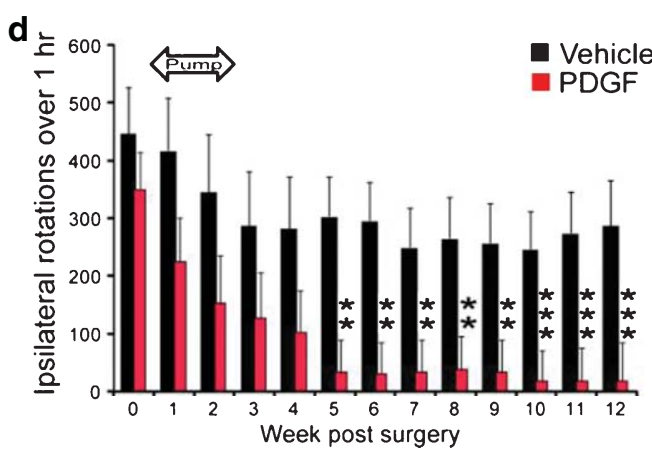

e $。$

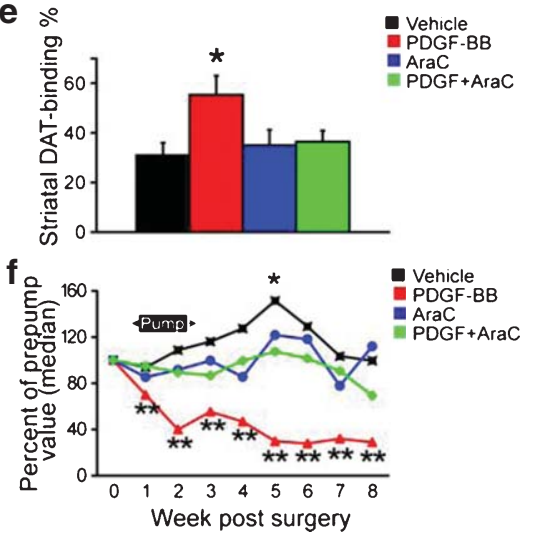

Fig. 2. Rodent models of PD. a, DAT binding; in mice that did not receive MPTP, levels of DAT binding were similar regardless of whether they were infused with vehicle or PDGF-BB. In mice treated with MPTP and then infused with vehicle, DAT binding was decreased by approximately $75 \%$. This reduction was significantly reversed in mice injected with MPTP and then infused with PDGF-BB; in these animals, levels of DAT were increased by $100 \%$. The graph shows median values \pm max, $\min .{ }^{*} p=0.029$, Mann-Whitney U-test, compared to MPTPvehicle, b, Photomicrographs showing BrdU positive cells in the MPTP lesioned mouse brain, c, Significant increase in number of BrdU positive striatal cells following treatment with PDGF-BB compared to vehicle in the MPTP lesioned mouse brain * $p<0.05$, Student's $t$-test. d, The effect of PDGF-BB (36 ng/day, 14 days; i.c.v.) on net ipsiversive rotations following amphetamine challenge (5 mg/kg; i.p.) in the 6-OHDA lesioned rat model of PD, $p<0.01$ lesion + treatment group, weeks 2-12 vs. week 0; two-way repeated measures ANOVA show significant effect with respect to treatment $\left(F_{1,25}=5.3724, p=0.02893\right)$ and Scheffe's post-hoc test revealed significant changes in average rotations at week 5-12, compared to baseline value (week 0 ) of the group selected for PDGF-BB treatment $\left(* *=p<0.01\right.$ and ${ }^{* * *}=p<0.001$ ). No difference in mean baseline rotation could be seen at week 0 when comparing the groups selected for vehicle and PDGF-BB treatment, respectively (nor were there any other significantly different means when comparing all against all). e, The effect of PDGF-BB (36 ng/day, 14 days; i.c.v.) in combination with Ara-C (120 ng/day, 14 days; i.c.v.) on striatal DAT binding. Data are presented as percentage binding compared to un-lesioned striatum. ${ }^{*} p<0.05$ compared to vehicle group; one-way ANOVA followed by Dunnett's test. f, The effect of PDGF-BB (36 ng/day, 14 days; i.c.v.) in combination with Ara-C (120 ng/day, 14 days; i.c.v.) on \% pre-pump rotations induced by amphetamine (5 mg/kg, i.p.) in the 6-OHDA lesioned rat model of PD. ${ }^{* *} p<0.01$ vs. week 0 ; one way repeated measures ANOVA followed by Dunnett's test.

\section{Motorbehavior and histology in Parkinsoninan rats}

To assess a potential PD-related behavioral effect following PDGF-BB treatment, including any association with cell proliferation, we used a partial unilateral 6-OHDA lesioned rat model. Animals presenting rotations when challenged with amphetamine alone, but not apomorphine, were considered partially lesioned [31]. The partially lesioned and fully lesioned vehicle treated rats had a significantly different loss of striatal DAT-binding (73.6\% and $91.7 \%$, respectively; $p=0.00689$, Student's $t$-test). We chose to administer PDGF-BB (36ng/day; i.c.v.) five weeks after the lesion (Fig. lc), to avoid assessing a more direct neuro- protective effect. A significant effect on amphetamine induced behavior was seen at 4-6 weeks after initiating the PDGF-BB treatment, i.e. 2-4 weeks after the end of treatment. The treatment resulted in a complete restoration of rotational asymmetry and the effect lasted until the study was terminated 10 weeks posttreatment (Fig. 2d). No difference with respect to baseline motor activity, when analyzed in an open field test, was seen in comparison to vehicle treated animals (data not shown). In contrast, rats that were shown to have a more complete lesion, based on their rotational behavior in response to apomorphine, did not show any significant improvement in behavior after the identical PDGF-BB treatment (data not shown). In apomorphine responsive rats, we could not detect 
a

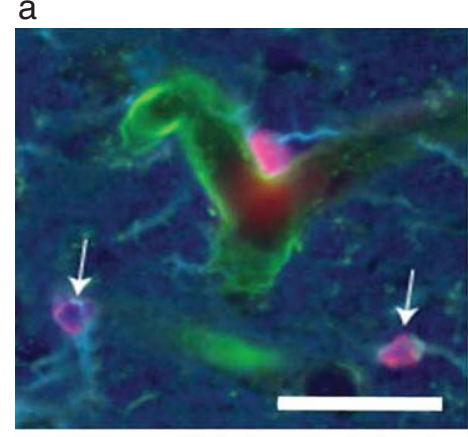

d

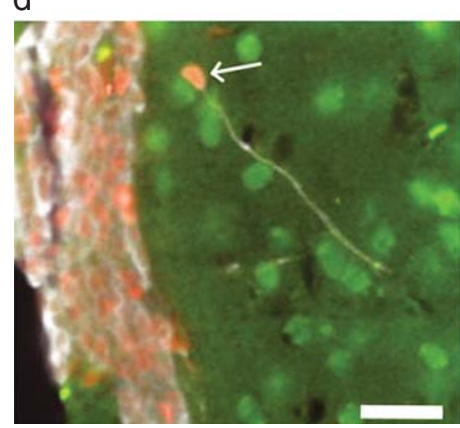

b

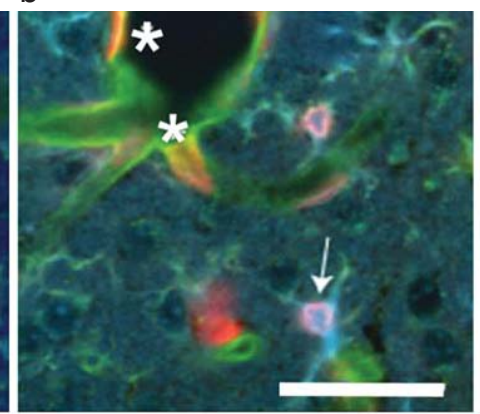

e

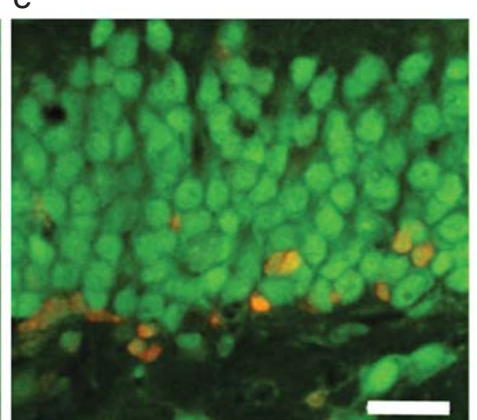

C

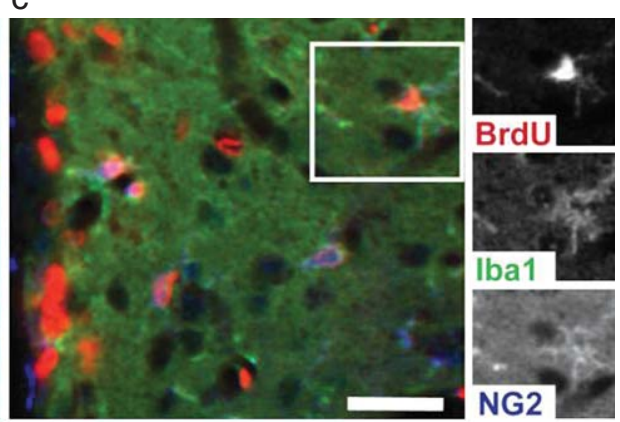

f

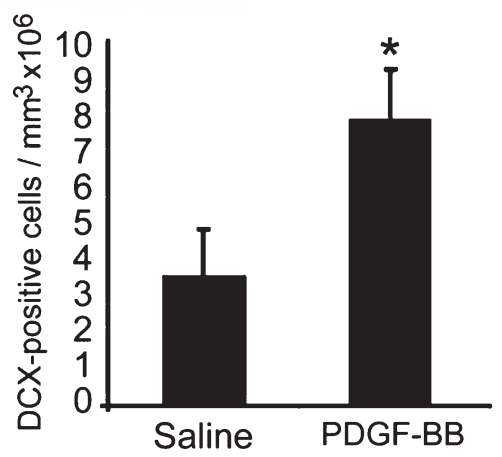

Fig. 3. The distribution and phenotype of newborn cells within the SVZ and adjacent striatum. a, Within the striatal parenchyma of either un-lesioned or MPTP lesioned animals, the predominant progenitor cell derived population were newborn NG2 oligodendrocytes, arrow in $(\mathrm{BrdU}=$ red and NG2 = blue). b, Because of the injury, newborn vascular cells (lectin-positive; green and asterisks) and microglia (Iba-1; blue and arrow) were abundant in tissues from all MPTP-treated mice. c, Most of the Ibal-positive monocytes (green) were co-decorated with NG2, (blue). d, Although rarely, we did find evidence for recruitment of neurogenesis within the MPTP-lesioned striatal parenchyma $(\mathrm{dcx}=$ white, $\mathrm{BrdU}=$ red, NeuN = green) either with or without PDGF-BB treatment, but were able to easily detect BrdU-labeled NeuN-positive neurons within the hippocampus ( $\mathrm{e} ; \mathrm{NeuN}=$ green, $\mathrm{BrdU}=\mathrm{red}), \mathrm{d}$ and $\mathrm{f}$, Consistent with the findings in rats, we did note an increase in the number of Dcx-positive progenitors in the more ventral regions of the SVZ proper. Scale bars $=50 \mu \mathrm{m}$ in a and b, $20 \mu \mathrm{m}$ in c-e.

TH containing fibers in the SVZ, while such fibers were present in all partially lesioned animals, treated and untreated (Fig. 4a). The magnitude of the proliferative response to $\mathrm{PDGF}-\mathrm{BB}$, i.e. increased number of BrdU positive cells was similar in rats irrespective of the degree of lesion. No turning behavior could be induced in sham lesioned animals, neither following vehicle nor following PDGF-BB treatment.

\section{Functional effects in relation to proliferation}

To investigate whether a relationship existed between the behavioral/histological/biochemical improvements caused by PDGF-BB and its proliferative effects, we used the mitotic blocker Ara-C [24] at a dose $(10 \mathrm{mg} / \mathrm{ml})$ that reduced PDGF-BB-induced proliferation by $70 \%$. In 6-OHDA lesioned rats (Fig. 1d), co-administration of Ara-C with PDGF-BB impeded the effects of PDGF-BB on striatal DAT binding and amphetamine induced rotations (Fig. 2e, f), as well as TH expression in SNpc (Fig. 5a-d).
The underlying structural restorative mechanism was further analyzed in a separate study in mice. PDGF-BB was administered i.c.v. for 7 days, starting $3 \mathrm{hr}$ after a partial MPTP-induced lesion $(40 \mathrm{mg} / \mathrm{kg}$, s.c.; Fig. 1b). Compared to untreated animals, there was an increased number of TH immunoreactive/cresyl violet staining neurons in $\mathrm{SNpc}$ as well as an increased density of $\mathrm{TH}$ positive fibers in the dorsal striatum following PDGF-BB treatment at eight weeks, but not at 1 week, post treatment (Fig. 6). Taken together, these findings in rodents suggest a delayed, cell proliferation-dependent structural and functional restorative effect on the DAergic system mediated by PDGF-BB.

\section{Expression of PDGF receptors in rats}

PDGF-BB is known to activate both PDGF-alpha and -beta receptors. In the rat, the PDGF receptor (PDGFR) -alpha was expressed in cells of the SVZ (Fig. 4b). Proliferating cells were abundant in the SVZ 

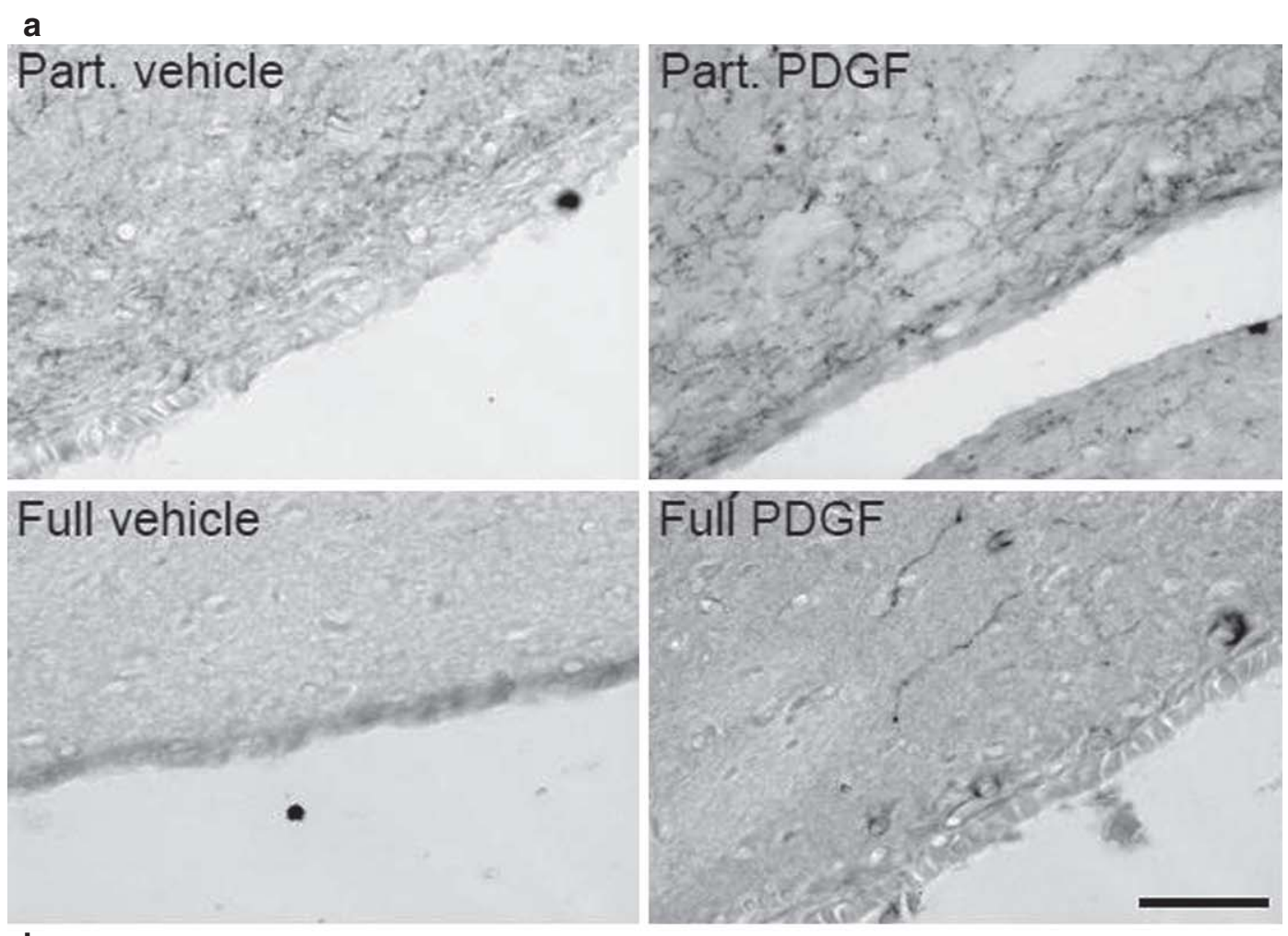

b

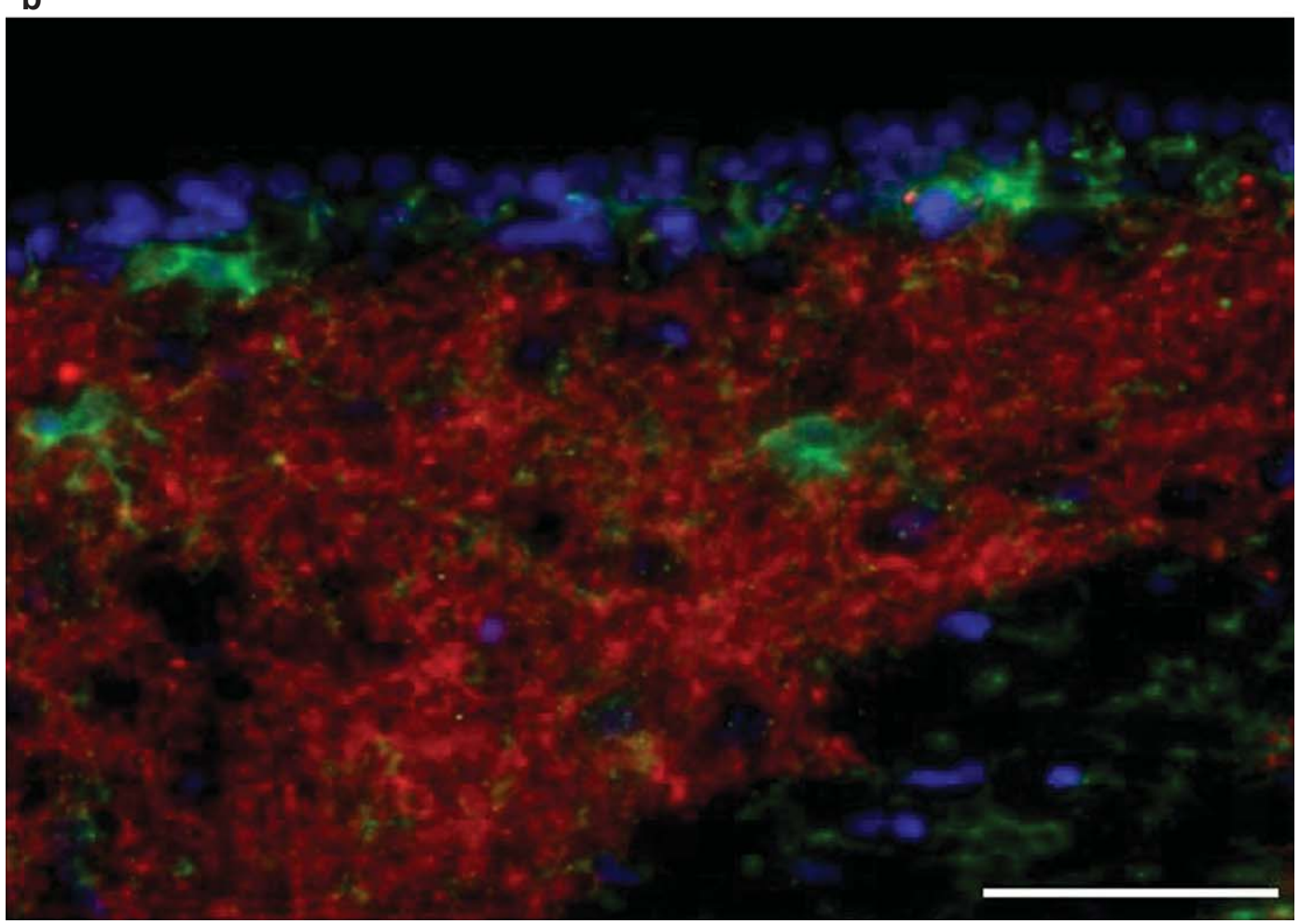

Fig. 4. Striatal micrographs. a, TH fibers in the medial striatum and SVZ following two weeks of vehicle or PDGF-BB treatment in partially vs. fully 6-OHDA lesioned rats. b, the presence of PDGFR-alpha positive cells (green) in proximity to TH fibers (red) in the SVZ and medial striatum. The nuclear stain DAPI is seen in blue. Scale bars $=50 \mu \mathrm{m}$. 

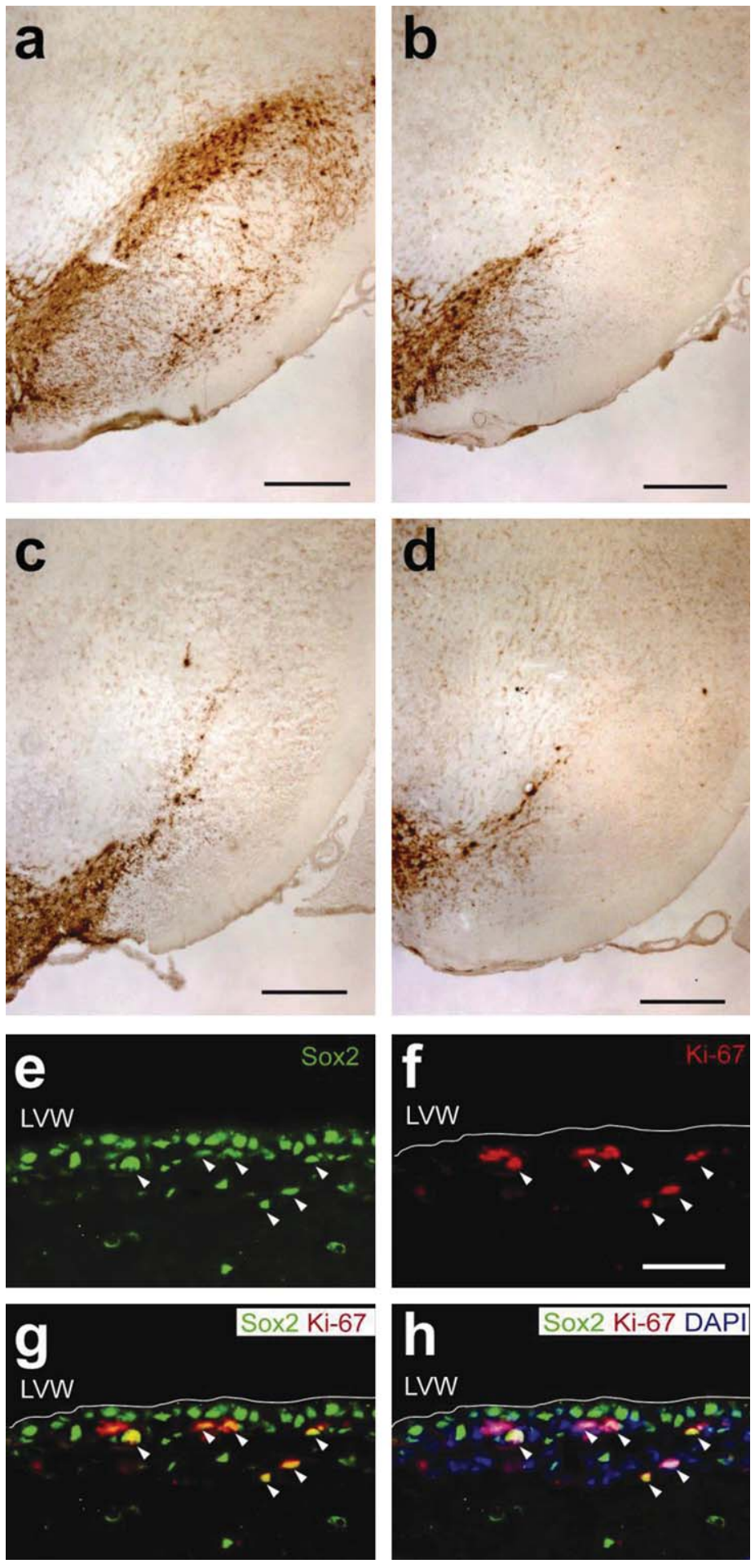

Fig. 5. Immunohistochemistry in rat SNpc and SVZ. a, Clear upregulation of TH expression was seen at ten weeks after end of treatment with PDGF-BB alone compared to $b$, vehicle, c, Co-treatment with Ara-C or d, Ara-C alone did not show any upregulation. Scale bar $=500 \mu \mathrm{m}$. e-h, Partially lesioned 6-OHDA rat brain treated with PDGF-BB ( $36 \mathrm{ng} /$ day) by continuous i.c.v. infusion during 14 days, e, Photomicrographs show Sox2 positive (green) multipotent progenitor cells. f, Ki67 positive (red) proliferating cells, g, co-localization of Sox2 and Ki67 in several cell nuclei (white arrow heads) along the lateral ventricle wall. h, DAPI was used as nuclear stain. The same region is shown in (e-h) (LVW =lateral ventricle wall; scale bar $=50 \mu \mathrm{m}$ ) 

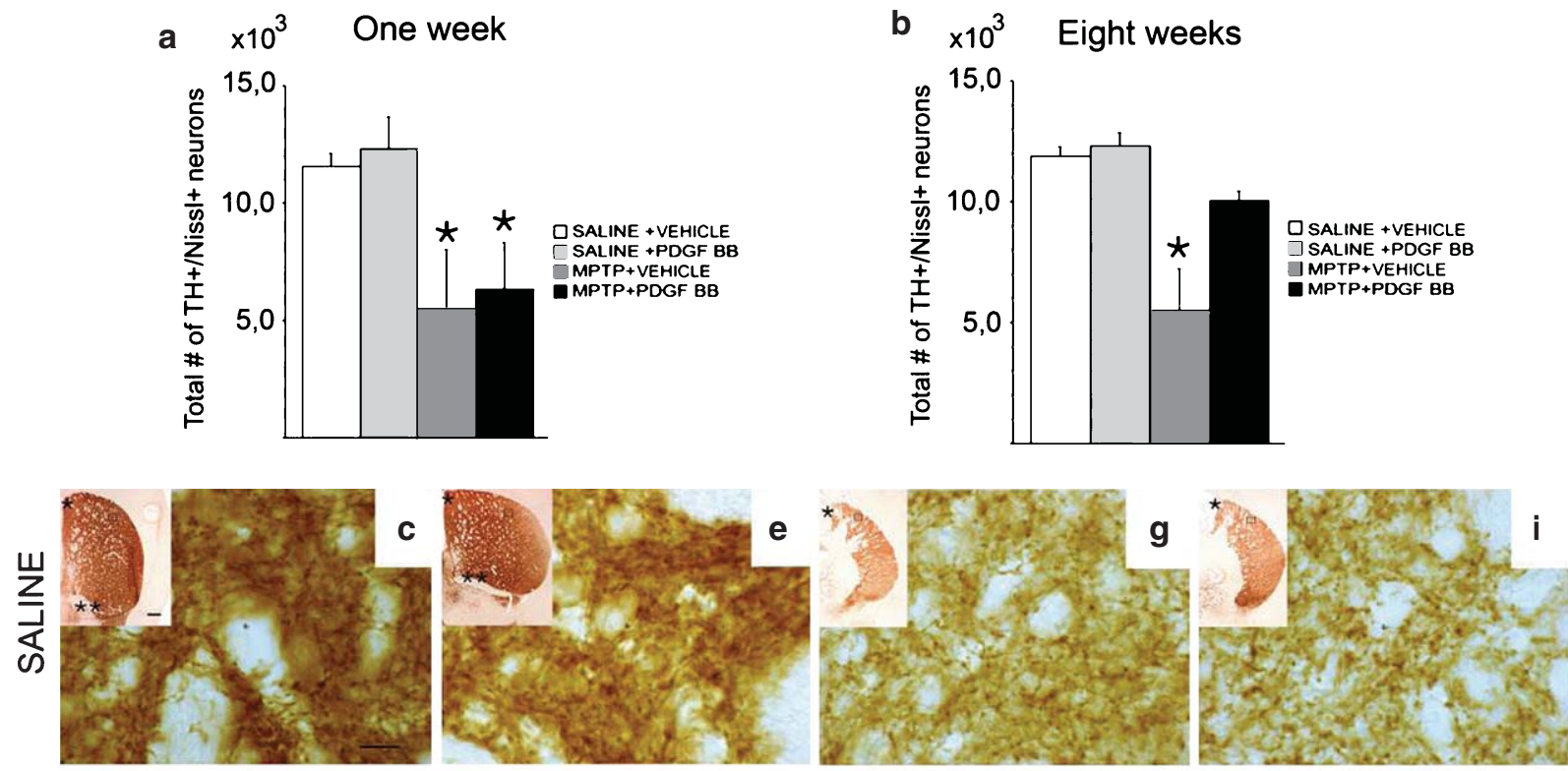

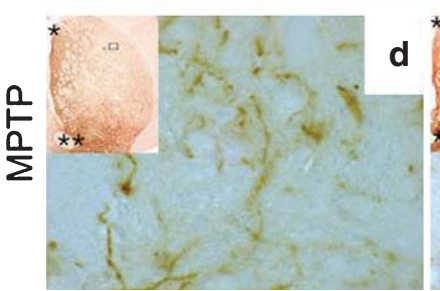

VEHICLE

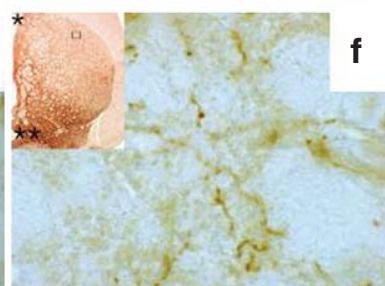

PDGF-BB One week

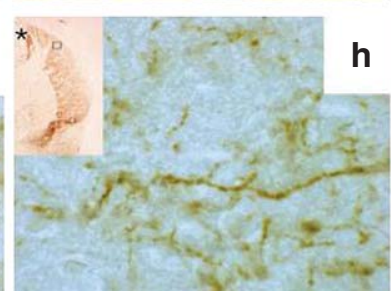

VEHICLE

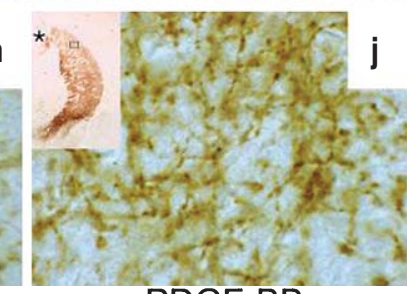

PDGF-BB

Fig. 6. Quantification of TH expression, a, Means \pm S.D. of stereological cell counts of $\mathrm{TH}$ positive/Nissl stained neurons in SNpc in mice treated with PDGF-BB starting $3 \mathrm{~h}$ after a single injection of MPTP $(40 \mathrm{mg} / \mathrm{kg}$, sc) are shown at one week post-lesion and b, at eight weeks post-lesion. PDGF-BB (60 ng/day, approximately $2.4 \mu \mathrm{g} / \mathrm{kg} / \mathrm{day}$ for seven days) significantly restored nigral neuronal loss at eight weights, but not at one week post-lesion (ANOVA, Scheffe's post - hoc, ${ }^{*} p<0.05, N=3-6$ in each group). Representative photomicrographs of TH immunoreactivity in the dorsal striatum after a similar MPTP lesion protocol in mice receiving PDGF-BB (36 ng/day) are shown with low magnifications inserted in the upper left corner $(\mathrm{bar}=200 \mu \mathrm{m}$, $*=$ dorsal striatal corner next to the left lateral ventricle, $* *=$ anterior commissure, rectangle illustrates sample area for high magnification). $\mathrm{c}-\mathrm{f}$, High magnification of TH positive nerve terminal networks are shown at one week post-lesion and $\mathrm{g}-\mathrm{j}$ at eight weeks post-lesion, $\mathrm{c}$, No difference is observed in the non-lesioned mice in the mid-striatum, vehicle versus e, PDGF-BB, one week post-lesion or in the caudal striatum, g, vehicle versus i, PDGF-BB, eight weeks post-lesion. j, In contrast, a robust increase in nerve terminal TH expression is seen after PDGF-BB (36 ng/day, approximately $1.4 \mu \mathrm{g} / \mathrm{kg} / \mathrm{day}$ for seven days) in the MPTP lesioned mouse at eight weeks post-lesion, compared to, $\mathrm{h}$, the vehicle treated lesioned mouse. At one week post-lesion no difference is seen between the two treatment groups, $\mathrm{f}, \mathrm{MPTP}+\mathrm{PDGF}-\mathrm{BB}$, versus d, MPTP+vehicle. Bar in high magnification = $10 \mu \mathrm{m}$.

and frequently stained positive for Sox2, based on costaining with Ki67 (Fig. 5e-h). In proximity to the SVZ, some cells co-expressing Sox2 and PDGFRalpha could be seen (Fig. 7). The PDGFR-beta was also expressed in cells of the SVZ and medial striatum but more predominantly on vascular pericyte cells although proximal RECA positive endothelial cells did not appear to express the receptor on the examined sections (Fig. 8).

\section{DISCUSSION}

The data in this study demonstrate that PDGF-BB is effective in counteracting histological, behavioral and biochemical changes in experimental rodent models of PD. In the 6-OHDA-lesioned rat, normalization of the rotational behavior after PDGF-BB treatment lasted for 10 weeks. Co-administration of Ara-C abolished the effects, demonstrating for the first time a functional 


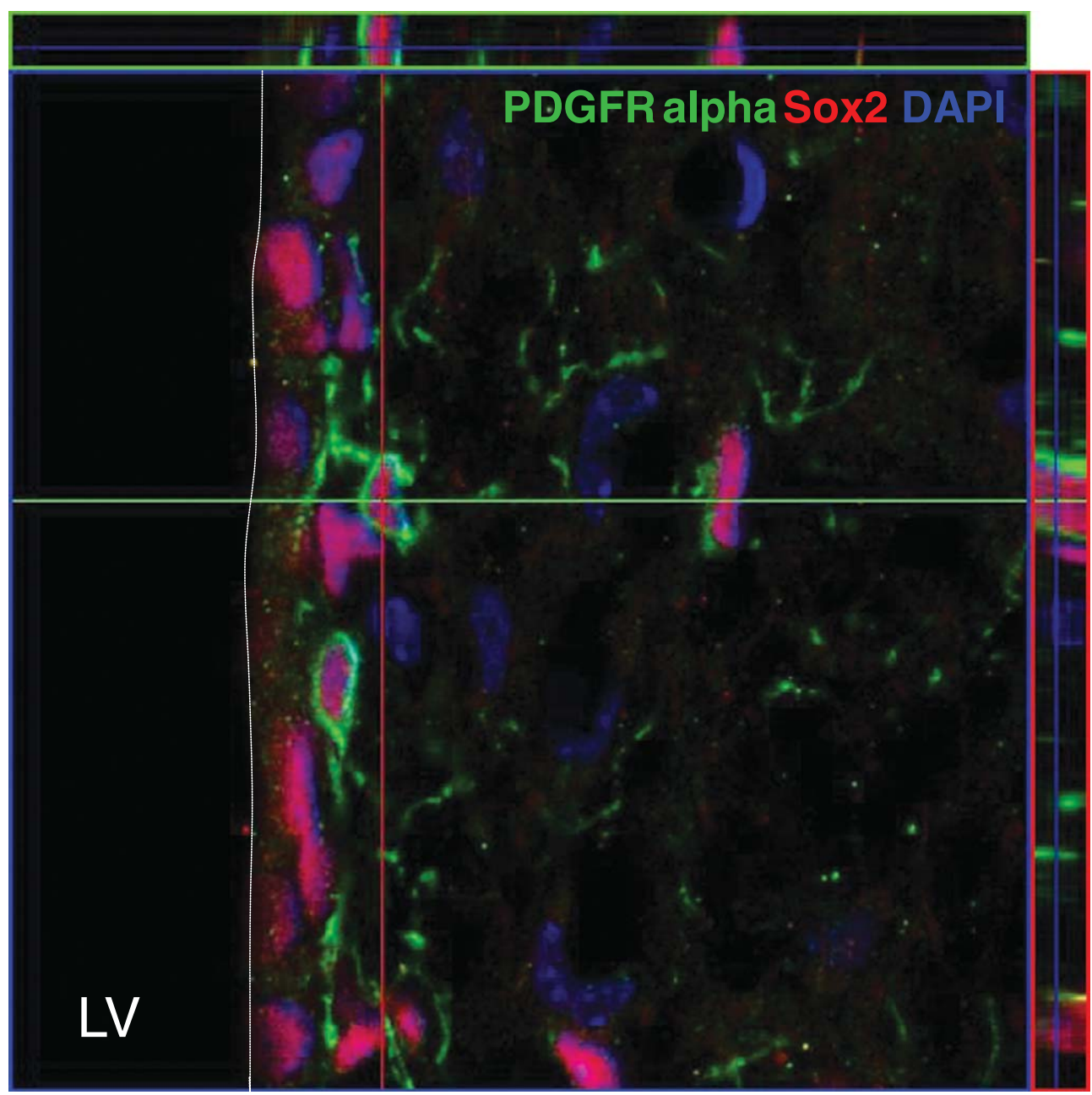

Fig. 7. In the rat SVZ, PDGFR-alpha (green) was found to be co-expressed by a subset of Sox2-positive cells (red) as shown by confocal microscopy. DAPI (blue) was used as nuclear stain. LV, lateral ventricle.

relevance of a PDGF-induced cell proliferation in a model of CNS disease. The most abundant cell types appearing in the SVZ and most medial parts of the striatum as a result of PDGF-treatment, were positive for markers of progenitor/precursor cells, i.e. NG2, Dcx, and Sox2, the latter being a marker of early neural progenitors with retained multipotency and self-renewal capacities [40]. Our data imply that proliferating and partially maturing cells in the stem and progenitor cell niche of the SVZ can elicit long lasting influence on the DAergic system. Other contributing factors, e.g. direct neuroprotection and/or cell-genesis in $\mathrm{SNpc}$, cannot be completely ruled out, however [34, 38, 46, 47]. The PDGF-R-beta is expressed on cells found in close proximity to vessels which may be pericytes. There was no apparent vascular proliferation seen in response to PDGF-BB stimulation in the rat, suggesting that the effects of PDGF-BB on the DAergic system were unlikely to be mediated by vascular cells.

Both PDGF-alpha and beta receptor chains are expressed on cells that express markers associated with progenitor cell properties [21, 22]. Thus, PDGF-BB has the ability to stimulate several progenitor-like cell types, while this might not be the case for PDGFAA and PDGF-CC, which are limited to activation of alpha-alpha and alpha-beta receptor dimers [26]. In a recent paper [41], PDGF-CC was shown to be neuroprotective for DAergic neurons after direct administration into the $\mathrm{SN}$ and also to increase the expression of multiple neurotrophic factors both in the brain and the retina. Given the overlap in receptor activation properties between the - $\mathrm{BB}$ and $-\mathrm{CC}$ isoforms, it 


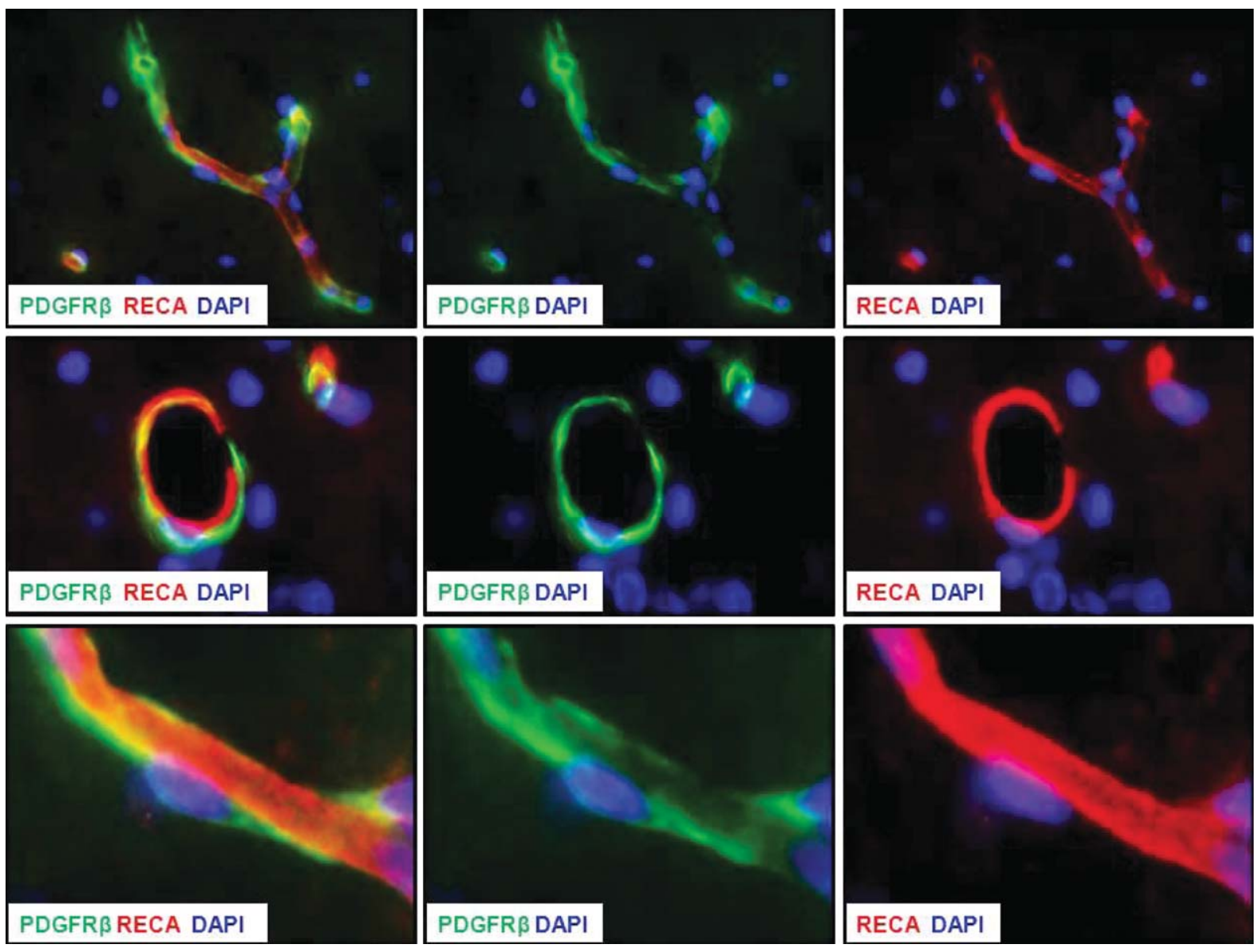

Fig. 8. In adult rat brain, PDGFR-beta (green) was predominantly expressed by pericytes. Endothelial cells expressing RECA (red) are surrounded by PDGFR-beta expressing pericytes (green) in the brain microvasculature (top row). A brain capillary in striatum showing a single RECApositive endothelial cell (red) closely attached to a PDGFRbeta-positive pericyte (green) (middle and bottom row). Nuclei was stained with DAPI (blue).

is possible that up-regulation of trophic factor expression by dividing cells or their progeny contribute to the PDGF-BB mediated effects.

The pattern of receptor expression and proliferative response in combination with the lack of therapeutic effect in Ara-C treated rats in our study, support a hypothesis whereby PDGF responsive proliferating cells mediate the effect on the DAergic system. The molecular basis of this effect warrants further investigation in models in which specific cell types can be selectively manipulated.

Other trophic factors, i.e. epidermal growth factor (EGF), fibroblast growth factor-2 (FGF-2), brain derived neurotrophic factor (BDNF) and transforming growth factor alpha (TGF $\alpha$ ) administered into the ventricles of experimental animals can promote an increase in the mitotic activity of progenitor cells, migration of progenitor cells into nearby areas (includ- ing the striatum) and differentiation into cells of both neuronal and glial lineage [14, 29, 37]. BDNF has been proven effective in models of PD [1, 42]. A dependency on cell proliferation for the therapeutic effect elicited in animals has not been described for BDNF. In the rat the BDNF receptor, TrkB, is not expressed on dividing cells, supporting a protective mechanism of action on more differentiated cells [37]. EGF and FGF-2 have been tested in models of PD, and were found to have positive effects on various aspects of the DAergic system when given shortly (up to 4 hours) after toxic injury [7, 19]. Conflicting results have been presented regarding effects of TGFa in models of PD $[9,14]$.

Glial Derived Growth Factor (GDNF) and Nerve Growth Factor (NGF) have previously been delivered via the i.c.v. route with limited success. Repeated bolus doses of GDNF to PD patients was clinically 
unsuccessful, possibly due to poor tissue penetration to dopaminergic target cells and fibers [32]. NGF caused aberrant pain sensations in patients with Alzheimer's disease, attributable to effects on sensory afferent fibers in dorsal root ganglia [11]. PDGF as a potential therapeutic might not suffer from poor tissue penetration since, as observed in this study, it targets cells in the peri-ventricular areas. Furthermore, potential sideeffects induced by PDGF will most likely be dependent on PDGF-receptor distribution in the human brain, spinal and cord and meninges.

In general, mobilization of adult progenitor cells, whether induced by injury itself or through pharmacological intervention, does not appear to generate a significant number of mature differentiated DAergic neurons $[9,30]$. Thus, if one assumes that neurorestoration and a clinically relevant effect in PD only can be achieved through a replacement of damaged DAergic neurons, the experimental evidence so far has not been strongly encouraging. Many different cell types seems to be produced following the infusion of PDGF-BB, raising the possibility that both neural and nonneuronal progeny may indirectly provide meaningful restorative or protective effects [30]. Interestingly, cell transplantation experiments using non-differentiated adult SVZ derived neural stem/progenitor cells transplanted to striatum caused a significant behavioral improvement in a rat model of PD [39]. Undifferentiated neural cell lines have also been shown to release factors that benefit regeneration processes in the CNS [27]. The specific cell type/s and the molecular mechanisms mediating the positive influence on the DA system following PDGF-BB treatment, remain to be elucidated.

The lack of behavioral and histological effects seen in fully lesioned animals ( $>90 \%$ lesion), with little or no DA fibers in close physical proximity to proliferating cells in SVZ is of both scientific and potential therapeutic relevance. It points to the issue of carefully assessing the degree of DAergic lesion when studying regenerative mechanisms. Interestingly, in patients, the loss of DAT-binding in the striatum does not reach $90 \%$, even in later stage PD (Hoehn \& Yahr III-IV) [44]. The loss of pigmented neurons in SNpc after 10 years duration of PD was reported to be 66\% [35]. DA fiber innervation of the SVZ as well as neural precursor cells are still present upon post mortem analysis [20], suggesting that the response elicited by PDGF$\mathrm{BB}$ treatment could be maintained in $\mathrm{PD}$ and be of therapeutic relevance.

In conclusion, our findings suggest a new approach for repairing a dysfunctional DAergic system and point to PDGF-BB as a promising new drug that, by stimulating progenitor cells, could have a significant impact on the treatment of PD.

\section{ACKNOWLEDGEMENTS}

The authors thank Drs Jonas Frisén and Lars Olson for fruitful discussions. As indicated, several authors are employed by a privately owned company. The work was also supported by a grant from the Swedish Medical Research Council 10816 and the Parkinson foundation in Sweden (Parkinsonfonden).

\section{REFERENCES}

[1] Altar CA, Boylan CB, Jackson C, Hershenson S, Miller J, Wiegand SJ, Lindsay RM, \& Hyman C (1992) Brain-derived neurotrophic factor augments rotational behavior and nigrostriatal dopamine turnover in vivo. Proc Natl Acad Sci U S A, 89, 11347-11351.

[2] Baker SA, Baker KA, \& Hagg T (2004) Dopaminergic nigrostriatal projections regulate neural precursor proliferation in the adult mouse subventricular zone. Eur J Neurosci, 20, 575-579.

[3] Barnéoud P, Parmentier S, Mazadier M, Miquet JM, Boireau A, Dubédat P, \& Blanchard JC (1995) Effects of complete and partial lesions of the dopaminergic mesotelencephalic system on skilled forelimb use in the rat. Neuroscience, 67, 837-848.

[4] Bertilsson G, Patrone C, Zachrisson O, Andersson A, Dannaeus K, Heidrich J, Kortesmaa J, Mercer A, Nielsen E, Ronnholm H, \& Wikstrom L (2008) Peptide hormone exendin-4 stimulates subventricular zone neurogenesis in the adult rodent brain and induces recovery in an animal model of Parkinson's disease. J Neurosci Res, 86, 326-338.

[5] Bezard E, Boraud T, Chalon S, Brotchie JM, Guilloteau D, \& Gross CE (2001a) Pallidal border cells: an anatomical and electrophysiological study in the 1-methyl-4-phenyl-1,2,3,6tetrahydropyridine-treated monkey. Neuroscience, 103, 117123

[6] Bezard E, Dovero S, Prunier C, Ravenscroft P, Chalon S, Guilloteau D, Crossman AR, Bioulac B, Brotchie JM, \& Gross CE (2001b) Relationship between the appearance of symptoms and the level of nigrostriatal degeneration in a progressive 1-methyl-4-phenyl-1,2,3,6-tetrahydropyridinelesioned macaque model of Parkinson's disease. J Neurosci, 21, 6853-6861.

[7] Chadi G, Moller A, Rosen L, Janson AM, Agnati LA, Goldstein M, Ogren SO, Pettersson RF, \& Fuxe K (1993) Protective actions of human recombinant basic fibroblast growth factor on MPTP-lesioned nigrostriatal dopamine neurons after intraventricular infusion. Exp Brain Res, 97, 145-158.

[8] Chan P, Di Monte DA, Langston JW, \& Janson AM (1997) (+)MK-801 does not prevent MPTP-induced loss of nigral neurons in mice. $J$ Pharmacol Exp Ther, 280, 439-446.

[9] Cooper O \& Isacson O (2004) Intrastriatal transforming growth factor alpha delivery to a model of Parkinson's disease induces proliferation and migration of endogenous adult neural progenitor cells without differentiation into dopaminergic neurons. J Neurosci, 24, 8924-8931.

[10] Emond P, Garreau L, Chalon S, Boazi M, Caillet M, Bricard J, Frangin Y, Mauclaire L, Besnard JC, \& Guilloteau D 
(1997) Synthesis and ligand binding of nortropane derivatives: N-substituted 2beta-carbomethoxy-3beta-(4'-iodophenyl)nortropane and $\mathrm{N}$-(3-iodoprop-(2E)-enyl)-2beta-carbomethoxy-3beta- $\left(3^{\prime}, 4^{\prime}\right.$-disubstituted phenyl)nortropane. New high-affinity and selective compounds for the dopamine transporter. J Med Chem, 40, 1366-1372.

[11] Eriksdotter Jönhagen M, Nordberg A, Amberla K, Bäckman L, Ebendal T, Meyerson B, Olson L, Seiger, Shigeta M, Theodorsson E, Viitanen M, Winblad B, \& Wahlund LO (1998) Intracerebroventricular infusion of nerve growth factor in three patients with Alzheimer's disease. Dement Geriatr Cogn Disord, 9, 246-257.

[12] Erlandsson A, Enarsson M, \& Forsberg-Nilsson K (2001) Immature neurons from CNS stem cells proliferate in response to platelet-derived growth factor. $J$ Neurosci, 21, 3483-3491.

[13] Erlandsson A, Brannvall K, Gustafsdottir S, Westermark B, \& Forsberg-Nilsson K (2006) Autocrine/paracrine plateletderived growth factor regulates proliferation of neural progenitor cells. Cancer Res, 66, 8042-8048.

[14] Fallon J, Reid S, Kinyamu R, Opole I, Opole R, Baratta J, Korc M, Endo TL, Duong A, Nguyen G, Karkehabadhi M, Twardzik D, Patel S, \& Loughlin S (2000) In vivo induction of massive proliferation, directed migration, and differentiation of neural cells in the adult mammalian brain. Proc Natl Acad Sci U S A, 97, 14686-14691.

[15] Freed CR, Greene PE, Breeze RE, Tsai WY, DuMouchel W, Kao R, Dillon S, Winfield H, Culver S, Trojanowski JQ, Eidelberg D, \& Fahn S (2001) Transplantation of embryonic dopamine neurons for severe Parkinson's disease. N Engl J Med, 344, 710-719.

[16] Freundlieb N, Francois C, Tande D, Oertel WH, Hirsch EC, \& Hoglinger GU (2006) Dopaminergic substantia nigra neurons project topographically organized to the subventricular zone and stimulate precursor cell proliferation in aged primates. J Neurosci, 26, 2321-2325.

[17] Gross CE, Ravenscroft P, Dovero S, Jaber M, Bioulac B, \& Bezard E (2003) Pattern of levodopa-induced striatal changes is different in normal and MPTP-lesioned mice. J Neurochem, 84, 1246-1255.

[18] Guilloteau D, Emond P, Baulieu JL, Garreau L, Frangin Y, Pourcelot L, Mauclaire L, Besnard JC, \& Chalon S (1998). Exploration of the dopamine transporter: in vitro and in vivo characterization of a high-affinity and high-specificity iodinated tropane derivative (E)-N-(3-iodoprop-2-enyl)-2betacarbomethoxy-3beta-(4'-m ethylphenyl)nortropane (PE2I). Nucl Med Biol, 25, 331-337.

[19] Hadjiconstantinou M, Fitkin JG, Dalia A, \& Neff NH (1991) Epidermal growth factor enhances striatal dopaminergic parameters in the 1-methyl-4-phenyl-1,2,3,6-tetrahydropyridine-treated mouse. J Neurochem, 57, 479-482.

[20] Hoglinger GU, Rizk P, Muriel MP, Duyckaerts C, Oertel WH, Caille I, \& Hirsch EC (2004) Dopamine depletion impairs precursor cell proliferation in Parkinson disease. Nat Neurosci, 7, 726-735.

[21] Ishii Y, Matsumoto Y, Watanabe R, Elmi M, Fujimori T, Nissen J, Cao Y, Nabeshima Y, Sasahara M, \& Funa K (2008) Characterization of neuroprogenitor cells expressing the PDGF beta-receptor within the subventricular zone of postnatal mice. Mol Cell Neurosci, 37, 507-518.

[22] Jackson EL, Garcia-Verdugo JM, Gil-Perotin S, Roy M, Quinones-Hinojosa A, VandenBerg S, \& Alvarez-Buylla A (2006) PDGFR alpha-positive B cells are neural stem cells in the adult SVZ that form glioma-like growths in response to increased PDGF signaling. Neuron, 51, 187-199.
[23] Janson AM \& Møller A (1993) Chronic nicotine treatment counteracts nigral cell loss induced by a partial mesodiencephalic hemitransection: an analysis of the total number and mean volume of neurons and glia in substantia nigra of the male rat. Neuroscience, 57, 931-941.

[24] Kokoeva MV, Yin H, \& Flier JS (2005) Neurogenesis in the hypothalamus of adult mice: potential role in energy balance. Science, 310, 679-683.

[25] Lang AE, Gill S, Patel NK, Lozano A, Nutt JG, Penn R, et al. (2006) Randomized controlled trial of intraputamenal glial cell line-derived neurotrophic factor infusion in Parkinson disease. Ann Neurol, 59, 459-466.

[26] Li X \& Eriksson U (2003) Novel PDGF family members: PDGF-C and PDGF-D. Cytokine Growth Factor Rev, 14, 91-98.

[27] Lu P, Jones LL, Snyder EY, \& Tuszynski MH (2003) Neural stem cells constitutively secrete neurotrophic factors and promote extensive host axonal growth after spinal cord injury. Exp Neurol, 181, 115-129.

[28] Marks WJ Jr, Bartus RT, Siffert J, Davis CS, Lozano A, Boulis N, Vitek J, Stacy M, Turner D, Verhagen L, Bakay R, Watts R, Guthrie B, Jankovic J, Simpson R, Tagliati M, Alterman R, Stern M, Baltuch G, Starr PA, Larson PS, Ostrem JL, Nutt J, Kieburtz K, Kordower JH, \& Olanow CW (2010) Gene delivery of AAV2-neurturin for Parkinson's disease: a doubleblind, randomised, controlled trial. Lancet Neurol, 9, 11641172 .

[29] Martens DJ, Seaberg RM, \& van der Kooy D (2002) In vivo infusions of exogenous growth factors into the fourth ventricle of the adult mouse brain increase the proliferation of neural progenitors around the fourth ventricle and the central canal of the spinal cord. Eur J Neurosci, 16, 1045-1057.

[30] Mohapel P, Frielingsdorf H, Haggblad J, Zachrisson O, \& Brundin P (2005) Platelet-derived growth factor (PDGF-BB) and brain-derived neurotrophic factor (BDNF) induce striatal neurogenesis in adult rats with 6-hydroxydopamine lesions. Neuroscience, 132, 767-776.

[31] Moore AE, Cicchetti F, Hennen J, \& Isacson O (2001) Parkinsonian motor deficits are reflected by proportional A9/A10 dopamine neuron degeneration in the rat. Exp Neurol, 172, 363-376.

[32] Nutt JG, Burchiel KJ, Cormella CL, Jankovic J, Lang AE, Laws ER Jr, Lozano AM, Penn RD, Simpson RK Jr, Stacy M, \& Wooten GF (2003) Randomized, double-blind trial of glial cell line-derived neurotrophic factor (GDNF) in PD. Neurology, 60, 69-73.

[33] Olanow CW, Goetz CG, Kordower JH, Stoessl AJ, Sossi V, Brin MF, Shannon KM, Nauert GM, Perl DP, Godbold J, \& Freeman TB (2003) A double-blind controlled trial of bilateral fetal nigral transplantation in Parkinson's disease. Ann Neurol, 54, 403-414.

[34] Othberg A, Odin P, Ballagi A, Ahgren A, Funa K, \& Lindvall O (1995) Specific effects of platelet derived growth factor (PDGF) on fetal rat and human dopaminergic neurons in vitro. Exp Brain Res, 105, 111-122.

[35] Pakkenberg B, Moller A, Gundersen HJ, Mouritzen Dam A, \& Pakkenberg H (1991) The absolute number of nerve cells in substantia nigra in normal subjects and in patients with Parkinson's disease estimated with an unbiased stereological method. J Neurol Neurosurg Psychiatry, 54, 30-33.

[36] Paxinos G, Watson CR, \& Emson PC (1980) AChE-stained horizontal sections of the rat brain in stereotaxic coordinates. J Neurosci Methods, 3, 129-149.

[37] Pencea V, Bingaman KD, Wiegand SJ, \& Luskin MB (2001) Infusion of brain-derived neurotrophic factor into the lat- 
eral ventricle of the adult rat leads to new neurons in the parenchyma of the striatum, septum, thalamus, and hypothalamus. J Neurosci 21, 6706-6717.

[38] Pietz K, Odin P, Funa K, \& Lindvall O (1996) Protective effect of platelet-derived growth factor against 6-hydroxydopamineinduced lesion of rat dopaminergic neurons in culture. Neurosci Lett, 204, 101-104.

[39] Richardson RM, Broaddus WC, Holloway KL, \& Fillmore HL (2005) Grafts of adult subependymal zone neuronal progenitor cells rescue hemiparkinsonian behavioral decline. Brain Res, 1032, 11-22.

[40] Suh H, Consiglio A, Ray J, Sawai T, D’Amour KA, \& Gage FH (2007) In vivo fate analysis reveals the multipotent and self-renewal capacities of sox2(+) neural stem cells in the Adult Hippocampus. Cell Stem Cell, 1, 515-528.

[41] Tang Z, Arjunan P, Lee C, Li Y, Kumar A, Hou X, Wang B, Wardega P, Zhang F, Dong L, Zhang Y, Zhang SZ, Ding H, Fariss RN, Becker KG, Lennartsson J, Nagai N, Cao Y, \& Li $X$ (2010) Survival effect of PDGF-CC rescues neurons from apoptosis in both brain and retina by regulating GSK3beta phosphorylation. J Exp Med, 207, 867-880.

[42] Tsukahara T, Takeda M, Shimohama S, Ohara O, \& Hashimoto N (1995) Effects of brain-derived neurotrophic factor on 1-methyl-4-phenyl-1,2,3,6-tetrahydropyridine-induced parkinsonism in monkeys. Neurosurgery, 37, 733-739; discussion 739-741.
[43] Walters TL, Irwin I, Delfani K, Langston JW, \& Janson AM (1999) Diethyldithiocarbamate causes nigral cell loss and dopamine depletion with nontoxic doses of MPTP. Exp Neurol, 156, 62-70.

[44] Wang J, Zuo CT, Jiang YP, Guan YH, Chen ZP, Xiang JD, Yang LQ, Ding ZT, Wu JJ, \& Su HL (2007) 18F-FP-CIT PET imaging and SPM analysis of dopamine transporters in Parkinson's disease in various Hoehn \& Yahr stages. J Neurol, 254, 185-190.

[45] Winkler EA, Bell JAD, \& Zlokovic BV (2010) Pericytespecific expression of PDGF beta receptor in mouse models with normal and deficient PDGF beta receptor signaling. Mol Neurodegener, 5, 32.

[46] Zhao M, \& Janson Lang AM (2009) Bromodeoxyuridine infused into the cerebral ventricle of adult mice labels nigral neurons under physiological conditions-a method to detect newborn nerve cells in regions with alow rate of neurogenesis. J Neurosci Methods, 184, 327-331.

[47] Zhao M, Momma S, Delfani K, Carlen M, Cassidy RM, Johansson CB, Brismar H, Shupliakov O, Frisen J, \& Janson AM (2003) Evidence for neurogenesis in the adult mammalian substantia nigra. Proc Natl Acad Sci U S A, 100, 7925-7930. 